\title{
JOGOS DE SUSTENTABILIDADE E ECO DESIGN: ESTRATEGIA DE ENSINAGEM CINESTÉSICA
}

\author{
Ana Verónica Pazmino, Dra. (UFSC)
}

\author{
PALAVRAS CHAVE \\ Jogos, Sustentabilidade, Pedagogia do Design. \\ KEY WORDS \\ Games, Sustainability, Design Education
}

\section{RESUMO}

O artigo apresenta a fundamentação teórica do jogo no ensino, o relato do desenvolvimento e da aplicação de jogos de sustentabilidade e eco design como etstratégia de ensinagem cinestésica na disciplina de Design e Sustentabilidade oferecida no curso de graduação em Design da UFSC. O trabalho contribui na pedagogia do design mostrando a importância do jogo como uma estratégia pedagógica que busca facilitar o aprendizado dos temas tratados na disciplina de forma que o aluno aprenda de forma lúdica e que possa reconhecer a complexidade e responsabilidade como designer e cidadão na conjuntura social - ambiental.

\section{ABSTRACT}

Article presents the theoretical foundation of game in teaching, relates the development and implementation of sustainability and eco design games as a teaching and learning strategy kinesthetic in the discipline of Design and Sustainability which was given in the graduation course in Design at UFSC. The work contributes to the design education showing a pedagogical strategy that seeks to facilitate the learning of the topics discussed in the course so that the student is able to work in teams and playful way to be able to recognize the complexity and responsibility as a designer and citizen in the conjuncture social - environmental. 


\section{INTRODUÇÃO}

A realidade da sala de aula do ensino superior precisa ser repensada de forma que concepções e práticas de ensinar e aprender sejam prazerosas tanto para o professor quanto para o aluno. Este artigo propõe jogos de sustentabilidade e eco design como estratégia de ensinagem cinestésica para a disciplina de Design e Sustentabilidade no curso de Design da UFSC. O trabalho mostra uma sustentação teórica pedagógica da necessidade de repensar as práticas em sala de aula.

Posteriormente é descrito o desenvolvimento de jogos pelos alunos da disciplina e a aplicação dos mesmos com outra turma. Finalmente, são descritos os resultados da ação pedagógica.

\section{FUNDAMENTAÇÃO TEORICA}

O exercício da docência no ensino superior visa à formação do aluno com uma visão de totalidade. A aprendizagem exige a compreensão do conteúdo pelo aluno. Perrenoud (2002) menciona que os professores universitários aprendem com a experiência, melhoram com o passar dos anos e terminam construindo uma forma de didática.

A didática definida como a técnica de dirigir e orientar a aprendizagem tem como subcampos as metodologias do ensino e as práticas de ensino. Dentre estas, se tem ferramentas para viabilizar o ensino. Desta forma, se uma parte dos professores ocupa sua função sem ter nenhuma formação didática, suas metodologias e práticas de ensino são resultado da prática cotidiana.

Para Costa e De Pesce (2008), compreender como o aluno adulto aprende pode ajudar o professor a propor e usar inovações metodológicas e tecnológicas. As autoras mencionam que as pesquisas sobre como os adultos aprendem são poucas em comparação às direcionadas às crianças, mas citam alguns resultados, como por exemplo:

- os adultos são motivados a aprender quando possuem necessidades e interesses que a aprendizagem poderá satisfazer. Estes devem ser o ponto de partida para organizar atividades;

- a orientação de adultos para a aprendizagem é centrada na vida, portanto as unidades apropriadas para esse caso são situações reais;

- a experiência é o recurso mais rico para aprendizagem de adultos, então a metodologia básica da educação de adultos é a análise da experiência;

- os adultos têm uma grande necessidade de serem auto dirigidos. Assim, o papel do professor é engajar-se em um processo de mútua investigação em lugar de transmitir o seu conhecimento e avaliar a adequação deles em relação ao processo;

- as diferenças individuais entre as pessoas aumentam com a idade. Por isso, a educação de adultos deve considerar as diferenças de estilo, tempo, local e ritmo de aprendizagem.

Assim sendo, no momento em que as aulas são planejadas e vão ser determinados os procedimentos e estratégias a serem utilizados no processo de ensino aprendizagem, deve ser considerado o modo como o aluno aprende.

Teixeira (2006) Menciona que o único teste da qualidade de uma experiência de aprendizagem está no fato dela ser bem ou mal sucedida, em provocar a desejada mudança no comportamento do aluno. Dessa forma, o autor reforça que um nível de aprendizagem, no seu sentido amplo, é uma expressão que reproduz uma mudança desejada. Essa mudança pode ocorrer em ações, pensamentos sentimentos e atitudescomo resultado de uma "experiência de aprendizagem", isto é, por um método de ensino adequado.

Ausubel et al. (1980 apud Castanho 2001, p.157) Afirma que quando um novo conhecimento é apresentado com os devidos cuidados para se articular com os já existentes na estrutura cognitiva do aluno, a aprendizagem significativa tem lugar.

Estes devidos cuidados devem atender os diferentes canais de percepção doser humano. 
Para Santos (2008, p.42) as três modalidades básicas responsáveis por processar informações e fixá-las na memória, resultam do desenvolvimento da preferência: visual (aprendizagem por meio da visão), a auditiva (aprendizagem por meio da audição) e a cinestésica (aprender interagindo/fazendo/sentindo).

Para recriar a vida acadêmica é preciso ter um entendimento das condições necessárias para que se processe a aprendizagem. Segundo Santos (2008, p.33) "a aprendizagem somente ocorre se quatro condições básicas forem atendidas: a motivação, o interesse, a habilidade de compartilhar experiências e a habilidade de interagir com os diferentes contextos". Para o autor se estas condições são atendidas, somadas aos processos gerais de aprendizagem torna-se possível o ato da aprendizagem significativa.

\subsection{JOGO COMO ESTRATÉGIA DE ENSI- NAGEM CINESTÉSICA}

Anastasiou (2006) ressalta que as estratégias de ensinagem visam à consecução de objetivos, portanto, há que se ter clareza sobre aonde se pretende chegar naquele momento com o processo de ensinagem. Por isso, os objetivos têm que estar muito claros tanto para o professor quanto para o aluno e devem estar registrados no programa de aprendizagem.

Em relação aos objetivos de aprendizagem segundo (GIL, 2008) podem ser classificados em três domínios: cognitivo, afetivo e psicomotor. Segundo o autor o domínio cognitivo refere-se aos objetivos ligados a conhecimentos, informações ou capacidades intelectuais. É o domínio que prevalece no ensino superior. $\mathrm{O}$ domínio afetivo atende aos objetivos relacionados com sentimentos, emoções, gostos ou atitudes. E o domínio psicomotor envolve os objetivos que enfatizam o uso de coordenação do corpo humano.

Anastasiou (2006) menciona que existe entre os docentes universitários um habitus [grifo do autor] de trabalho com predominância na exposição do conteúdo, em aulas expositivas ou palestras, leitura de textos, pesquisas etc., a configuração atual, tem a palestra como principal forma de trabalho. E os alunos esperam que o professor faça exposição dos assuntos a serem aprendidos. $O$ novo procedimento exige uma modificação dinâmica da aula.

Alvarez-Ballestero (2004) menciona que quanto mais o estudante avança pelos diversos níveis educativos, mais a aprendizagem se torna internalizada e menos externalizada; talvez por esse motivo, muitos alunos se tornam cada vez menos motivados quando recebem um ensino por meio de processos passivos e abstratos.

A aprendizagem cinestésica envolve desenvolver características como:

- aprender por meio da experiência direta e da participação;

- recordar com mais facilidade o que tenha feito e não o que tenha ouvido ou visto;

- divertir-se com experiências concretas na aprendizagem, tais como construção de modelos, participação em jogos, montagem de objetos.

Para Alvarez-Ballestero (2004) todos os indivíduos manifestam de alguma forma a tendência ou necessidade cinestésica, porém, aqueles que, literalmente, precisam "tocar" as ideias para compreendê-las saem bastante prejudicados quando o aprendizado multissensorial não ocorre. Para a autora, a aprendizagem cinestésica proporciona com frequência uma experiência educacional significativa, prazerosa e inesquecível. Uma das atividades cinestésicas que permitem auxiliar no ensino, é desenvolver jogos ou jogar em sala de aula.

Huizinga (2003) coloca os jogos em um patamar além do entretenimento, mostrando como eles fazem partem da natureza humana, de seus conflitos, de suas relações e criações.

Para Gil (2009) os jogos são atividades espontâneas realizadas por mais de uma pessoa, regidas por regras que determinam perda ou ganho. Os jogos podem ser simulados e não simulados. Para Gil, não simulados são os jogos em que o participante procura solucionar problemas utilizando alguns princípios. Os jogos simulados são aqueles em que os participantes são colocados frente a desafios que reprodu- 
zem a realidade.

Segundo Lara, 2001 (apud DAMASCENO et al., 2007) os jogos ultimamente vêm ganhando espaço dentro do ambiente de ensino, numa tentativa de trazer o lúdico para dentro de sala de aula.

Como atividade de ensino o jogo pretende auxiliar o aluno a pensar com clareza, desenvolvendo sua reflexão. Podendo ser utilizado para alcançar diversos objetivos dentro de um plano de ensino.

Fromberg (2002) apresenta as principais características do jogo que são:

Simbolismo, já que um objeto representa outro de forma analógica ou convencional (p. ex: um tabuleiro é o símbolo de um ambiente); Significação se baseia na relação de referência do símbolo; Voluntário ou intrinsecamente motivador usa elementos que provocam motivação e são realizados de forma voluntária; Episódico implica em ações que tem relação com outros fatos ligados a uma meta principal.

Segundo Gil (2009), o jogo ainda é mais difundido no ensino fundamental e médio, sobretudo porque é considerada uma estratégia para "aprender brincando".

Mas seu uso vem se ampliando no ensino superior. $\mathrm{O}$ autor menciona que apesar da crescente utilização de jogos no Ensino Superior, esta estratégia ainda é vista com certa desconfiança por alguns educadores.

Para Gil o jogo encoraja a cooperação entre os jogadores e proporciona um contexto adequado para o ensino pelos pares e para o desenvolvimento de comunidades de aprendizagem.

Dependo do contexto cultural, do campo de conhecimento, e os objetivos dos usuários, o jogo pode ter funções educativas nas diversas disciplinas. Para Gil (2009) os jogos contribuem para ativar conhecimentos anteriores, já que seu desenvolvimento requer o conhecimento de fatos e proporcionam imediato feedback. Alguns dos princípios pedagógicos presentes nos jogos são mostrados no Quadro 1.

\begin{tabular}{|c|l|}
\hline $\begin{array}{l}\text { Princípios peda- } \\
\text { gógicos }\end{array}$ & Aplicação em jogos \\
\hline Individualização & $\begin{array}{l}\text { Adaptam-se ao nível } \\
\text { do indivíduo. }\end{array}$ \\
\hline Feedback & $\begin{array}{l}\text { Provêm feedback } \\
\text { imediato e contextual- } \\
\text { izado. }\end{array}$ \\
\hline Aprendizado Ativo & $\begin{array}{l}\text { Provêm um ambiente } \\
\text { ativo que conduz a } \\
\text { descoberta. }\end{array}$ \\
\hline Socialidade & $\begin{array}{l}\text { Engajam os usuários } \\
\text { durante horas, buscan- } \\
\text { do alcançar os objeti- } \\
\text { vos. }\end{array}$ \\
\hline Avaliação & $\begin{array}{l}\text { Podem envolver out- } \\
\text { ros competidores. }\end{array}$ \\
$\begin{array}{l}\text { Possibilitam aos } \\
\text { usuários avaliar suas } \\
\text { habilidades zou con- } \\
\text { hecimentos e com- } \\
\text { pará-las com a dos } \\
\text { outros. }\end{array}$ \\
\hline
\end{tabular}

Gil (2009 menciona que como os jogos são inerentemente presenciais engajam diferentes sentidos no processo de aprendizagem. Estimulam a construção de hipóteses, pois o aprendizado ocorre por tentativa e erro. São motivadores, pois o sucesso requer o aprendizado do material. Os jogos inspiram os jogadores a procurar dados e informações e os educandos são encorajados a desafios.

Segundo Schell (2010) os elementos básicos de um jogo são:

- mecânica: envolve regras e definições. Mostra o jogo como será jogado e seu sistema formal.

- narrativa: pode ser uma história inserida com inicio meio e fim, servir apenas como pano de fundo ou serem narrativas emergentes que são construídas conforme a experiência do jogador. As histórias são importantes para possibilitarem maior profundidade e complexidade ao jogo, facilitando o processo de imersão. 
- estética: envolve a parte visual do jogo, seus elementos icônicos. Como ele se apresenta ao jogador.

- tecnologia: como será o suporte do jogo, físico ou virtual. Tabuleiro, cartas etc.

Percebendo a importância da aprendizagem cinestésica e os elementos de um jogo, a seguir é mostrado o desenvolvimento dos jogos realizados na disciplina de Design e Sustentabilidade.

\section{DESENVOLVIMENTO}

Para tornar a disciplina de Design e Sustentabilidade mais dinâmica, foram desenvolvidos jogos como estratégia de ensinagem cinestésica, objetivando que os alunos se tornem conscientes da própria atividade. Por outro lado, buscou-se enriquecer o processo de aprendizagem, complementando, exemplificando e apresentando os temas teóricos mostrados em sala de aula por meio das aulas expositivas dialogadas, estudo de texto e cine educação.

Cabe mencionar que a disciplina de Design e Sustentabilidade na UFSC, não é configurada como uma aula de projeto. Trata-se de uma disciplina teórica em que os alunos devem alcançar os seguintes objetivos: tal;

1. Compreender a problemática ambien-

2. Conhecer o percurso cronológico do novo paradigma ambiental;

3. Conhecer as propostas de novos cenários sustentáeis;

4. Conhecer os princípios do eco-design e da sustentabilidade;

5. Conhecer estratégias de desenvolvimento de produtos e serviços sustentáveis.

A estratégia de ensinagem cinestésica por meio do desenvolvimento do jogo visava colaborar para alcançar os objetivos 1, 2 e 3 . Além disso, outras estratégias de ensinagem como: aulas expositivas dialogadas, destinadas a abordar os diversos assuntos; estudos de texto por meio da leitura e comentário no ambiente virtual de livros relacionados e resenhas críticas de filmes. Foram as outras estratégias utilizadas para alcançar os objetivos da disciplina.

\subsection{ORIENTAÇÕES PARA O DESENVOLVI- MENTO DOS JOGOS}

As orientações para o desenvolvimento de jogos na turma de 2013/1 que contou com 40 alunos foram realizadas em sete ações.

1. Os alunos em equipes de cinco deviam desenvolver um jogo físico sobre design e meio ambiente, poderiam também informar e sensibilizar sobre as problemáticas ambientais e sociais: Água, Alimentação, Energia, Mobilidade, Lixo eletrônico, Consumo, Lixo orgânico, Lixo reciclável, Pobreza, Poluição (eletromagnética, sonora, química etc.), Perda da Biodiversidade e outras problemáticas podiam ser sugeridas pelos alunos.

2. Escolha de uma problemática e pesquisa aprofundada sobre o assunto;

3. Realizar uma análise de jogos, tanto pelo manual como "jogá-los" a fim de levantar as seguintes características:
a) Dinâmica;
b) Cores;
c) Complexidade;
d) Tempo de jogo;
e) Número de jogadores;
f) Tema;
g) Recursos;
h) Faixa etária;
i) Manual.

4. Processo criativo para definir a mecânica, narrativa, estética e a tecnologia; teste;

5. Confecção de modelo do jogo para

6. Desenvolvimento do manual;

7. Apresentação dos jogos.

A turma teve um semestre para trabalhar no desenvolvimento dos jogos e realização das atividades. Os jogos encontrados no mercado 
relacionados com ecologia e sustentabilidade que foram analisados e jogados em sala de aula como forma de obtenção de ideias para o desenvolvimento da mecânica dos jogos foram: Eco Fluxx, Recicle, Banco mobiliário sustentável e Jogo da Sustentabilidade. Outros jogos com temas diferentes incluiram: Robin Hood, The Game of Life e Colonizadores de Catan.

A turma desenvolveu 8 jogos. A seguir serão mostrados 6 que tiveram as melhores soluções em relação aos objetivos da disciplina.

\subsubsection{FOOT PRINT POKER}

O objetivo é conhecer a "pegada" ecológica de diversos países e assim ganhar as fichas de aposta dos outros jogadores.

Os componentes do jogo são: 50 cartas, 100 fichas de aposta (20 de cada cor), um dado, uma ficha de cor preta para diferenciar o jogador a iniciar as apostas.

A dinâmica do jogo permite que o jogador conheça a "pegada" ecológica de um país e qual parâmetro é o mais consumido. A figura 1 mostra o jogo Foot print poker.

O jogo reutilizou as embalagens de café para serem utilizadas como fichas. Um uso adequado devido à quantidade de embalagens coloridas de alumínio.

É uma ferramenta quantitativa que mede quantos recursos (florestas, pastagens, áreas construídas, estoques pesqueiros, áreas de cultivo, carbono) do meio ambiente são consumidos por uma pessoa, um país ou uma população. Seu cálculo é constantemente atualizado com novos dados sendo responsável a Global Footprint Network uma organização sem fins lucrativos.

O jogo se justifica devido aos impactos causados pelo consumo e pela indústria. O consumo representa a demanda sobre o ecossistema através da extração de recursos naturais, geração de lixo e poluição. Fatores como explosão demográfica, diminuição dos recursos naturais, aumento da poluição, desequilíbrios ecológicos e climáticos são assuntos preocupantes para a sociedade.

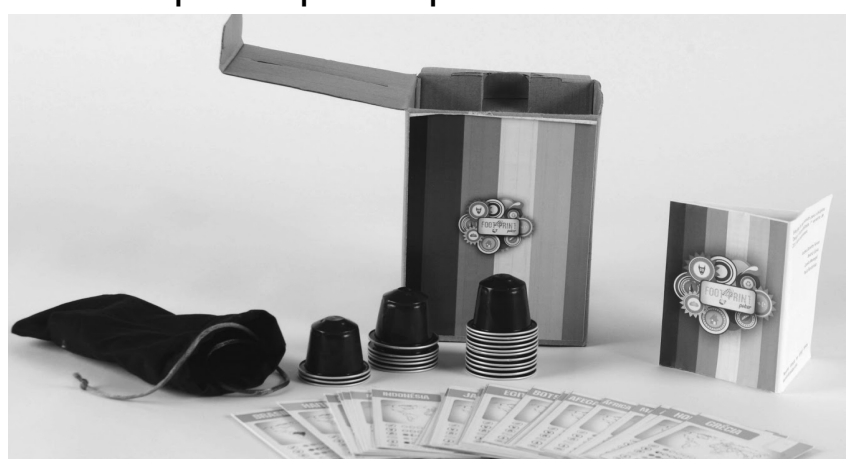

Figura 1-Foot print poker

Fonte: Autores

Para o cálculo desse consumo foi criado um indicador chamado de "Pegada Ecológica". O indicador mede o quanto cada pessoa poderia usar dos recursos naturais da Terra, em área, para viver, produzir e consumir. $\mathrm{O}$ conceito de Pegada Ecológica foi desenvolvido por Mathis Wackernagel e William Rees na publicação do livro "Our Ecological Footprint" em 1992 que sustenta que os recursos naturais são um bem finito.

O planeta possui cerca de 11,4 bilhões de hectares de terra e mar produtivos para fornecer sustento para a população mundial. Se divididos entre 7 bilhões de habitantes, a média é de 1,6 hectares por pessoa. A média nos EUA, por exemplo, chega a 9,6 hectares. $O$ índice ideal teórico, que indica quanto seria necessário para o desenvolvimento equilibrado do planeta, estabelece 1,6 hectares por pessoa. Cada um dos 7 bilhões de habitantes da Terra usa em média uma área de 2,3 hectares. (WACKERNAGEL, REES,1992)

A Terra não acompanha a voracidade do consumo, hoje se consome aproximadamente $27 \%$ a mais do que o planeta pode resistir para manter o equilíbrio. O jogo Foot print poker mostra que os países mais desenvolvidos tem uma "pegada" maior que a dos menos desenvolvidos. 


\subsubsection{SOLUCIONA}

O objetivo é refletir sobre o consumo e uma vida sustentável. Permite pensar em ideias criativas de design para a solução de problemas relacionados à problemática do consumo.

Componentes do jogo: um tabuleiro, uma ampulheta de 30 seg., 36 cartas briefing, 8 peões, oito blocos de anotações, oito lápis. A figura 2 mostra o jogo Soluciona.

Figura 2 -Soluciona

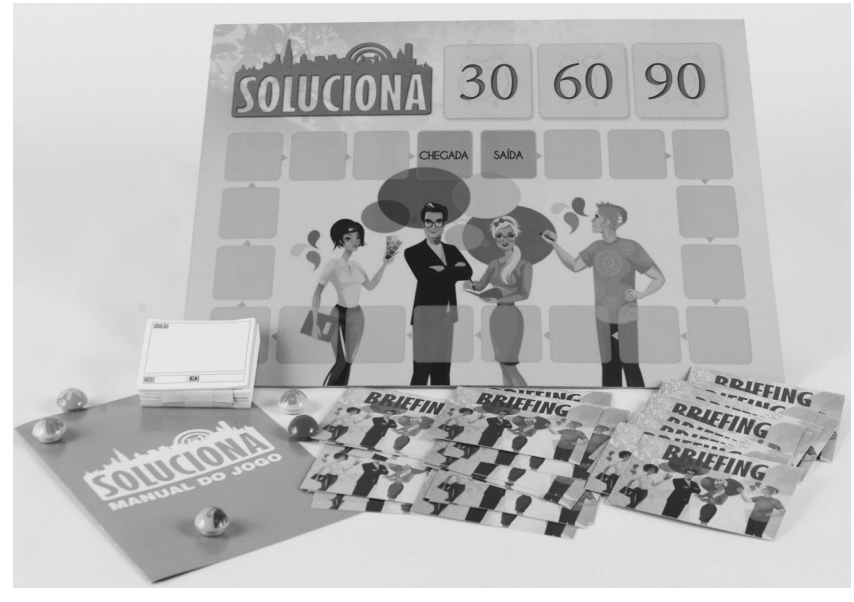

Fonte: Autores

O jogo possibilita que os participantes sugiram ideias mais sustentáveis e permite uma reflexão por meio da ferramenta do briefing. Relação com o design e sustentabilidade.

A pesquisa que sustenta o jogo é baseada no termo do economista Thorstein Vebleb criou o termo consumo conspícuo em 1899. Ele identificou pessoas ansiosas para mostrar sua riqueza e poder social por meio de roupas, bens visíveis e, que no Século $X X$, a produção industrial iniciou um grande crescimento com o desenvolvimento de novos processos produtivos com a introdução do Taylorismo .

Além disso, a criação de crédito de consumo em 1920 inicia um processo de consumo de massa elevado denominado como hiperconsumismo.

Outro fator determinante é o crescimento econômico dos países que passou a ser medido ,em 1948, pelo PIB - Produto Interno Bruto. $O$ indicador contabiliza o que foi produzido internamente em termos de bens e serviços - sem distinção entre o que é benéfico ou não para a sociedade e para o meio ambiente - e serve de instrumento de comparação macroeconômica entre as nações.

Botsman (2011) menciona que em 1932 o pioneiro da publicidade Earnest Elmo cunhou o termo "engenharia do consumo", ou seja, "fazer com que o consumidor consuma o tipo de produto que agora simplesmente utilizamos". O estilo de vida no ocidente adota o padrão do consumo e da renovação incentivada pela publicidade e pela divulgação da obsolescência. da tecnologia e da felicidade. Novos produtos e materiais a base do petróleo como o plástico criaram a cultura do descartável, uma cultura de descarte inconsequente.

Até o fim da década de 1980, muitos produtos ainda eram projetados para durar a vida toda. Uma câmera, uma máquina de escrever era algo que acompanhava um fotógrafo ou um escritor por toda sua carreira.

Para Sudjic (2010):

"Os bens que conservamos durante décadas podem ser considerados espelhos de nossas experiências da passagem do tempo. Agora, nossa relação com os novos bens parece muito mais vazia. A atração de um produto é criada e vendida na base de um olhar que não sobrevive ao contato físico".

E ainda destaca que "O desenho industrial começa a parecer uma forma de cirurgia plástica [...] para criar uma breve ilusão de beleza".

Nos últimos anos, os bens não apenas aumentaram em numero como em tamanho, telas de TV passaram de 28" para 60"(SUDJIC ,2010).

O sociólogo Robert K. Merton aponta duas fontes de consequências não intencionais relevantes para o consumo exagerado: a ignorância e o interesse imediatista (o indivíduo quer um produto ou ação ignorando consequências a longo prazo). Tanto os compradores como os fabricantes se envolvem em uma combinação destes efeitos a medida que eles participam do sistema consumista dos tempos atuais.

A relação do design neste ambiente complexo do comportamento da sociedade atual é tratada de forma leve no jogo para pensar de forma criativa oferecendo soluções mais ecológicas. 


\subsubsection{ECOOPERAÇÃO}

O objetivo do jogo é refletir sobre o lixo que se acumula no oceano. $O$ jogador por meio de cooperação e negociação deve retirar o lixo do centro até a borda avançando no tabuleiro.

Figura 3 - Ecooperação

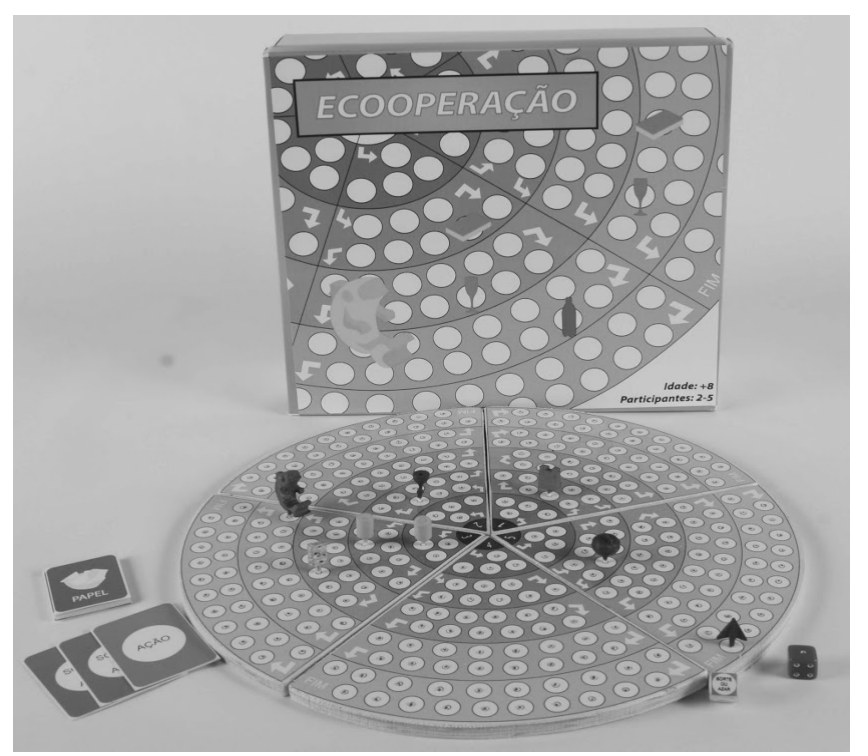

Fonte: Autores.

Componentes do jogo: um tabuleiro dividido em cinco territórios, cinco peões em forma de peixe, um dado comum, um dado sorte e azar, 30 cartas ação, 25 cartas sorte, 25 cartas azar, duas cartas coringa, 210 cartas de lixo (35 para cada tipo de lixo - vidro, plástico, papel, orgânico, não reciclável, metal), 130 unidades de lixo (30 peões que simbolizam seis tipos de lixo). A figura 3 mostra o jogo Ecooperação.

O jogo permite que o jogador perceba a quantidade de lixo existente no oceano e a necessidade de um trabalho de cooperação para solucionar o problema.

Durante a pesquisa foi levantado que países industrializados estão começando a enfrentar as consequências do rápido desenvolvimento das últimas décadas. A grande difusão de bens de consumo e o encurtamento de vida do produto deram lugar a uma quantidade crescente de produtos usados que são descartados.

"O Lixão do Pacifico", mostra uma área no oceano Pacífico norte onde correntes marítimas em forma de espiral concentram duas imensas áreas de lixos plásticos, estimado no tamanho dos estados Brasileiros de São Paulo, Rio de Janeiro, Minas Gerais e Goiás juntos e com uma profundidade de, aproximadamente, dez metros.

O jogo permite entender o filme "Viciados em Plástico - Ascensão e queda de um milagre moderno", (CONNACHER, Canadá, 2008) que mostra a realidade dos efeitos do plástico no oceano e as consequências nos animais que vivem nesse habitat.

\subsubsection{LINCE LIXO}

O objetivo é informar ao jogador detalhes sobre a correta identificação do lixo para um descarte adequado. A Figura 4 mostra o jogo:

Figura 4 - Lince Lixo

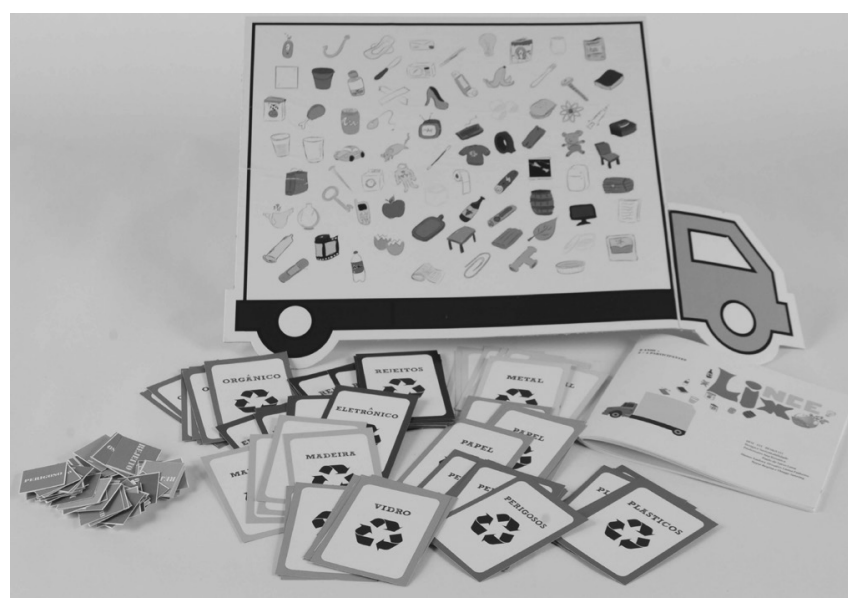

Fonte: Autores.

Componentes do jogo: um tabuleiro, uma ampulheta, 75 cartões (distribuídos em: nove perigosos, sete plásticos, 16 rejeitos, sete papel, sete orgânicos, oito eletrônicos, dez metais, seis vidros, e cinco madeiras), 450 mini cartões em quatro cores (50 cartões para nove tipos de lixo).

O jogo usa a analogia de fácil compreensão podendo ser jogado por adultos e crianças a partir dos oito anos.

Durante a pesquisa o grupo identificou 
que, atualmente, a produção anual de lixo do planeta é de aproximadamente 400 milhões de toneladas. O Brasil produz aproximadamente 240 mil toneladas de lixo por dia, a maior parte vai para lixões e aterros sanitários.

O lixo reciclável na maioria das vezes não é separado de forma adequada e é descartado provocando poluição, problemas sanitários e de contaminação. Em diversos países faltam aterros e causa a exportação de lixo.

\subsubsection{FAST OR GREEN}

Tem como objetivo completar todas as medidas sustentáveis de uma empresa e, assim, chegar ao fim do jogo com mais pontos. Para uma medida sustentável ser completada o peão deve dar uma volta completa no tabuleiro e retornar a empresa.

Componentes do jogo: um tabuleiro, 15 peões (três de cada cor), um dado, 48 cartas (24 verdes e 24 vermelhas). A Figura 5 mostra o jogo Fast or green.

Figura 5 - Fast or Green

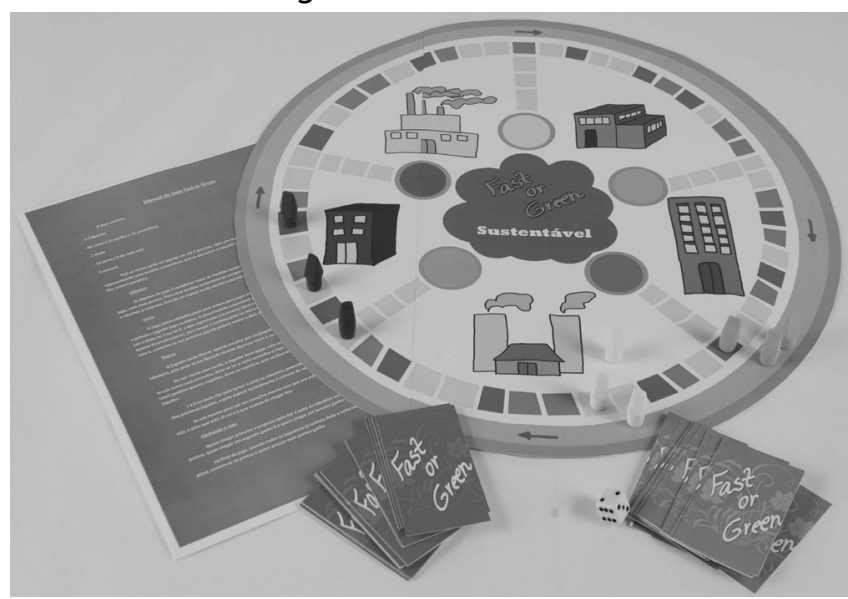

Fonte: Autores.

O jogo também é de fácil compreensão e pode ser jogado por crianças. Por meio de diversas situações o jogador pode encontrar no caminho problemas que os fazem demorar em completar o jogo ou se deparar com soluções sustentáveis para avançar rapidamente.

É importante conhecer que a poluição implica em prejudicar o meio ambiente e à saúde.
Abrange a contaminação por parte da queima de combustíveis, uso de pesticidas, uso de produtos tóxicos em produtos e alimentos, etc.

Os impactos à saúde humana e ao meio ambiente estão vinculados ao consumo e acontecem ao longo do ciclo de vida dos produtos, indústrias, alimentos, entre outros que estão inseridos na sociedade. Além destes também considera as contaminações dadas por substancias químicas nocivas ou em excesso que afetam o ecossistema.

\subsubsection{ISLAND RIDER}

Visa sensibilizar jovens de 11 a 18 anos por meio de um jogo de tabuleiro sobre os benefícios da bicicleta através da interação, diversão e competitividade. Busca enfatizar a sustentabilidade que envolve a utilização das bicicletas em um sistema urbano. A Figura 5 mostra o jogo.

Figura 6 - Island rider

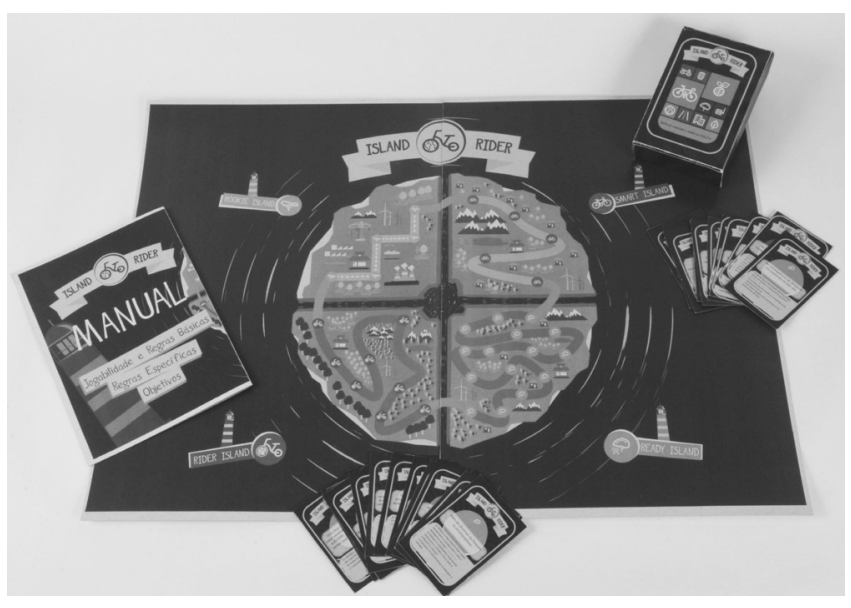

Possui tabuleiro de papel de tamanho A2, 40 CARTAS de papel com dimensões $-9 \mathrm{~cm} \times 6$ $\mathrm{cm}$ e quatro avatares de papel.

Os veículos consomem enormes quantidades de recursos na sua fabricação e utilizam muito espaço. (THACKARA, 2008) O jogo faz questionamentos como "Quantas pessoas percebem que $1 \mathrm{~h}$ de mobilidade por dia ao longo de um ano de trabalho totaliza um período de 
5 a 6 semanas em que poderia ter tirado de férias?"

Congestionamentos, poluição sonora, lixo, poluição do ar fazem do $\mathrm{CO}_{2}$ um dos vilões do efeito estufa. Mais de $1 / 4$ da emissão é gerada pelo setor de transportes rodoviário, marítimo e aéreo.

O jogo defende o uso de bicicleta para percursos de pouca distância e o conhecimento das vantagens físicas e ecológicas desse meio de transporte.

\section{APLICAÇÃO DOS JOGOS}

Os protótipos dos jogos foram aplicados com a turma de 2013/2 da disciplina de design e sustentabilidade, os alunos deviam responder um questionário. O objetivo foi levantar as qualidades e problemas do material para otimizar os jogos e poder aplicar como estratégia de ensinagem com outras turmas e em escolas do ensino fundamental e médio. Os itens avaliados no questionário foram: aparência do jogo (estética, acabamento); manual (clareza da informação, regras, qualidade gráfica); relação com a disciplina (narrativa, desafio compatível); mecânica (dinâmica adequada, engajamento do jogador, tecnologia adequada). Os alunos não precisavam se identificar e podiam fazer comentários ao final do questionário. A Figura 6 mostra os alunos jogando e avaliando os jogos.

Figura 6-Alunosjogando

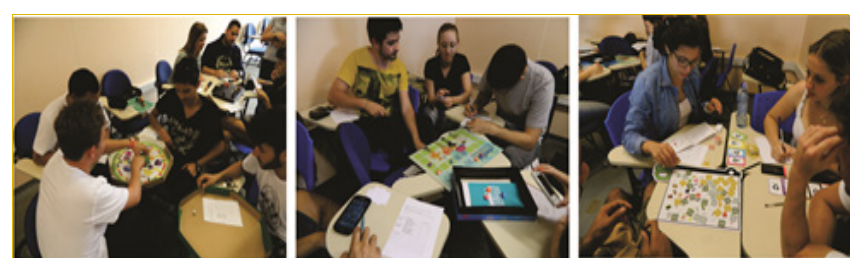

Fonte: Autores.

A turma de 2013/2 contava com 32 alunos, os mesmos avaliaram os jogos e preencheram os questionários. Percebeu-se que a estratégia foi bem recebida, houve descontração e ânimo para participar da atividade. Muitos jogaram sem concluir a leitura do manual (um compor- tamento normal, a preferência da tentativa e erro), alguns jogos foram curtos e puderam ser jogados por vários grupos, já outros jogos ocuparam o total da aula (3horas).

A tabulação do resultado dos questionários se encontra no Gráfico 1.

Gráfico 1 - Avaliação dos Jogos

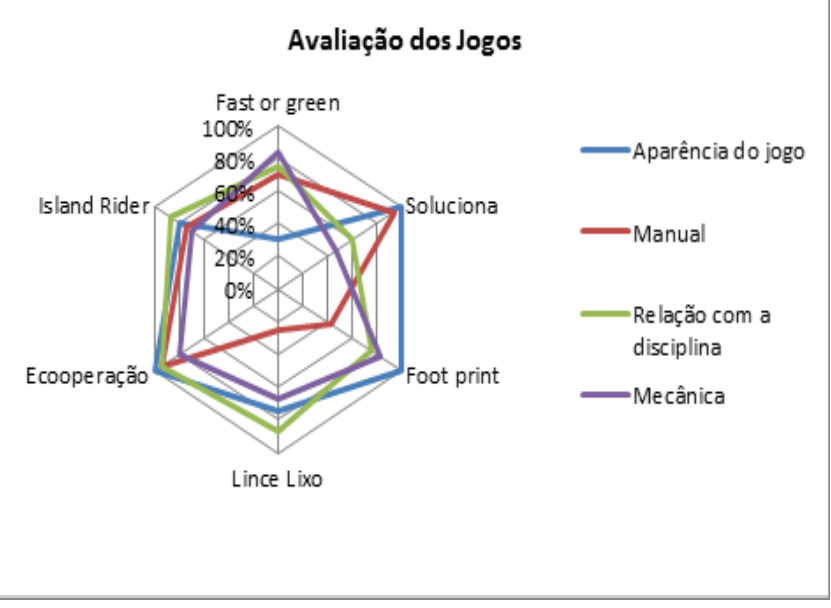

Fonte: Desconhecida.

Pelo gráfico pode-se perceber que no quesito da aparência dos jogos, Ecooperação, Soluciona e Foot Print tiveram a maior pontuação; no quesito manual, Ecooperação e Soluciona tiveram maior clareza e qualidade gráfica; na relação com a disciplina, todos os jogos atenderam, porém, nos comentários sobre a narrativa e desafios o jogo Foot Print foi a necessidade de ser mais bem explicados (muitos jogadores nunca tiveram contato com o jogo de poker); no quesito da mecânica, Lince Lixo e Fast or Green precisam otimizar a tecnologia.

Pelas avaliações da turma que desenvolveu os jogos e da turma que jogou, foi possível elaborar a estratégia de ensino cinestésico: desenvolvimento de jogo ou aplicação de jogo em sala de aula. O Quadro 1 mostra de forma esquemática a descrição da estratégia, os domínios da aprendizagem envolvidos, a dinâmica da atividade e uma forma de avaliação por parte do professor.

Em relação aos domínios de aprendizagem foram alcançados no domínio cognitivo: conhecimento (definir e identificar conceitos); compreensão (ilustrar situações e realidades, 
traduzir por meio de analogias e fatos concretos); aplicação (aplicar conceitos em situação prática); síntese (resumir um assunto de forma simples); avaliação (decidir os caminhos mais sustentáveis).

Quadro 1 - Estratégia de ensinagem cinestésica: jogos

\begin{tabular}{|c|c|}
\hline DESCRIÇÃO & Abrange o desenvolvimento de jogos e aplicação de jogos em sala de aula \\
\hline $\begin{array}{l}\text { DOMINIOS DA } \\
\text { APRENDIZAGEM }\end{array}$ & $\begin{array}{l}\text { Dominio Cognitivo: Conhecimento, Compreensão, Aplicação, Sintese } \\
\text { Avaliaçăo; } \\
\text { Dominio Afetivo: Receptividade, Resposta, Valorizaçăo, Organizaçăo, } \\
\text { Caracterização de um valor; } \\
\text { Domínio psicomotor: distinguir e comunicar }\end{array}$ \\
\hline $\begin{array}{l}\text { DINÂMICA DA } \\
\text { ATIVIDADE }\end{array}$ & $\begin{array}{l}\text { Para desenvolver um jogo } \\
\text { 1. O professor deve dividir os alunos em grupos de três ou mais; } \\
\text { 2. Passar o tema do jogo a ser desenvolvido } \\
\text { 3. Realizar uma análise de jogos } \\
\text { 4. Processo criativo para definir a mecânica, narrativa, estética e a } \\
\text { tecnologia. } \\
\text { 5. Confecçào de modelo do jogo para teste. } \\
\text { 6. Desenvolvimento do manual. } \\
\text { 7. Apresentaçáo dos jogos. } \\
\text { Jogo aplicado em sala de aula } \\
\text { 1. Escolher jogos relacionados com os temas tratados em aula; } \\
\text { 2. Dividiri os alunos em grupos de três ou mais (dependendo do jogo) } \\
\text { 3. Explicar o jogo a ser jogado (manual) } \\
\text { 4. Jogar } \\
\text { 4. Relatar a experiência }\end{array}$ \\
\hline AVALIAÇÃO & $\begin{array}{l}\text { Da participação oral de apresentação do jogo (quando desenvolvido) } \\
\text { Da participacăo no jogo e exposiçăo da experiência em termos de } \\
\text { conteúdos apreendidos. } \\
\text { Aplicação de questionário ou relato oral ou impresso }\end{array}$ \\
\hline
\end{tabular}

Fonte: Adaptado de Anastasiou (2006, p.79; GIL, 2008 p. 46-47)

Já no domino Afetivo: receptividade (perceber os problemas ambientais); resposta (acompanhar a dinâmica do jogo); valorização (reconhecer a complexidade da sustentabilidade, aceitar soluções pequenas como contribuição para solucionar problemas complexos); organização (desenvolver um jogo, discutir assuntos da disciplina); caracterização de um valor (revisar os pensamentos a partir dos temas tratados nos jogos).

E, por último o domínio psicomotor, onde além dos movimentos reflexos e básicos, a estratégia atende as habilidades perceptivas: distinguir formas de sintetizar a informação, uso de cores e formas análogas e comunicação não discursivas desde expressões faciais até comunicação pelas ações feitas durante o jogo.

\section{CONCLUSÃO}

O papel do professor no ensino superior de design é de formar pessoas, prepará-las para a vida, cidadania, treiná-las como agentes éticos e responsáveis do progresso social e am- biental. O professor deve mobilizar um conjunto de recursos e estratégias para ser o mediador desse processo de ensino-aprendizagem. No contexto educacional, os jogos são vistos como estratégias que facilitam a aprendizagem. Dessa forma, o artigo apresentou um recurso para o professor de disciplinas com abordagem ambiental e social relacionada ao design. $O$ desenvolvimento de jogos que abordam temas da disciplina e a aplicação dos mesmos oferece uma alternativa pedagógica adequada. $\mathrm{O}$ artigo relatou uma experiência positiva aplicando a estratégia de ensinagem cinestésica por meio de jogos de sustentabilidade no curso de Design da UFSC. Os materiais desenvolvidos após a avaliação foram melhorados e posteriormente aplicados com outras turmas.

Finalmente, cabe salientar que a estratégia de ensino por meio de jogos não deve ser a única estratégia em sala de aula, cabe ao professor utilizar diversas estratégias para que o processo de ensino-aprendizagem seja eficiente.

\section{REFERÊNCIAS}

ALVAREZ-BALLESTERO, María Esmeralda. Exercitando as inteligências múltiplas: Dinâmicas de grupo fáceis e rápidas para o ensino superior. São Paulo: Papirus Editora, 2004.

ANASTASIOU, Léa das Graças Camargos. Ensinar, aprender, apreender e processos de ensinagem. In. Processos de ensinagem na universidade: pressupostos para as estratégias de trabalho em aula. / organizado por ANASTASIOU e ALVES. 6. ed.- Joinville, SC: UNIVILLE, 2006.

BOTSMAN, Rachel; ROGERS, Roo. O que é meu é seu como o consumo colaborativo vai mudar o nosso mundo. Porto Alegre. Bookman. 2011.

CASTANHO, Maria Eugênia. Sobre professores marcantes. In Temas e textos em metodologia do ensino superior. Organizado por CASTA$\mathrm{NHO}$, Sergio e CASTANHO, Maria Eugenia. Papirus Editora, 83-102 pp. 2001.

COSTA, lara Andrade; DE PESCE, Marly Krüger. 
Inovação metodológica para além do recurso tecnológico. In. Revista Univille. Universidade da Região de Joinville. V.13, n.1 (2008).-Joinville, SC: Univille, 2003.

DAMASCENO, Ana Maria; MERCADO, Luís Paulo; ABREU de, Nitecy Gonçalves. Formando professor pesquisador do ensino médio. Maceió: EDUFAL, 2007.

FROMBERG, Doris Pronin. Play and Meaning in Early Childhood Education. Ed. Allyn and Bacon, 2002.

GIL, Antônio Carlos. Didática do ensino superior. São Paulo: Editora Atlas, 2009.

Metodologia do ensino superior. São

Paulo: Atlas, 2008.

HUIZINGA, Johan. Homo Ludens. Portugal: Edições 70. 2003

PERRENOUD, Philippe. A prática reflexiva no ofí68 cio do professor. Profissionalização e Razão pedagógica. Porto Alegre: Editora Artmed, 2002.

SCHELL, Jesse. A arte do game design. Rio de Janeiro: Editora Campus/Elsevier. 2010.

SUDJIC, Deyan. A linguagem das coisas. Intrínseca. Rio de Janeiro, 2010.

THACKARA, J. Plano B: o design e as alternativas viáveis em um mundo complexo. São Paulo: Saraiva: Versar, 2008.

TEIXEIRA, Gilberto. Elaboração de objetivos educacionais no ensino superior. In: Ser professor universitário, 2006. (http://www.serprofessoruniversitario.pro.br) 